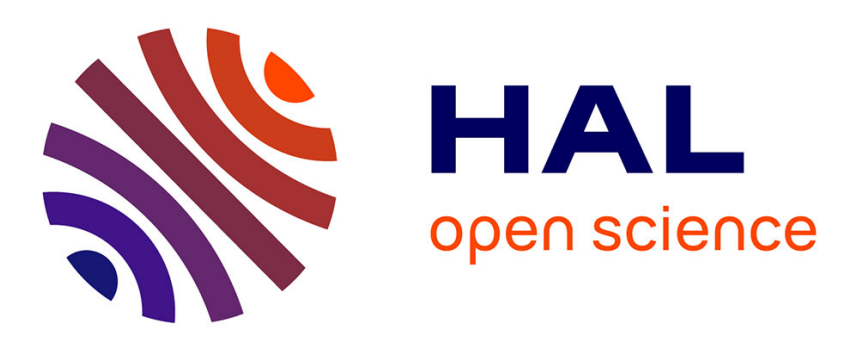

\title{
Simultaneous assessment of bone thickness and velocity for ultrasonic computed tomography using transmission-echo method
}

\author{
Rui Zheng, Philippe Lasaygues
}

\section{- To cite this version:}

Rui Zheng, Philippe Lasaygues. Simultaneous assessment of bone thickness and velocity for ultrasonic computed tomography using transmission-echo method. Ultrasonics symposium (IUS), 2013 IEEE International, 2013, pp.2084-2087. 10.1109/ULTSYM.2013.0532 . hal-00947406

\author{
HAL Id: hal-00947406 \\ https://hal.science/hal-00947406
}

Submitted on 18 Feb 2014

HAL is a multi-disciplinary open access archive for the deposit and dissemination of scientific research documents, whether they are published or not. The documents may come from teaching and research institutions in France or abroad, or from public or private research centers.
L'archive ouverte pluridisciplinaire HAL, est destinée au dépôt et à la diffusion de documents scientifiques de niveau recherche, publiés ou non, émanant des établissements d'enseignement et de recherche français ou étrangers, des laboratoires publics ou privés. 


\section{Simultaneous Assessment of Bone Thickness and Velocity for Ultrasonic Computed Tomography Using Transmission-Echo Method}

\author{
Rui Zheng \\ Dept. of surgery \\ University of Alberta \\ Edmonton, AB, Canada \\ rui.zheng@ualberta.ca
}

\author{
Philippe Lasaygues \\ Laboratory of Mechanics and Acoustics \\ Aix-Marseille University UPR CNRS 7051 \\ Marseille, France \\ Lasaygues@1ma.cnrs-mrs.fr
}

\begin{abstract}
The robustness and accuracy of the transmissionecho (TE) method is investigated on simultaneous thickness and velocity estimation of double-layered thin bone samples. Twentytwo pairs of bovine cortical samples were assembled and measured by two pairs of immersion transducers with nominal frequencies of $1 \mathrm{MHz}$ and $2.25 \mathrm{MHz}$. For each measurement, the TOF of six pulses contained by one transmission and two echo signals were detected and then used for the calculation. The mean relative errors of effective samples for $1 \mathrm{MHz}$ and $2.25 \mathrm{MHz}$ transducers are $4.87 \%$ and $7.13 \%$ on cortical thickness estimation, and $4.65 \%$ and $5.88 \%$ on velocity assessment, respectively. The method shows more stability on velocity measurement. For both thickness and velocity measurement, the experiments in low frequency provide more accurate estimations than high frequency. It is demonstrated that the TE method shows a potential to simultaneously estimate the cortical thickness and ultrasonic wave velocity for the mimic model of long bones.
\end{abstract}

Keywords - transmission-echo method; bone thickness; bone velocity; initial modeling; ultrasonic imaging.

\section{INTRODUCTION}

Ultrasonic computed tomography (UCT) based on inversion scattering theory has been developed and in vitro applied to the measurement of long bone samples such as cross-sectional imaging of children femurs and cortical thickness estimation based on the reconstructed inner structures [1][2]. It is of great importance to establish more accurate and precise initial models before the inversion procedure, for the acoustical impedance contrast level between the hard tissue (bone) and the background (soft tissues in vivo or water in vitro) is very high for long bone structures [3]. Therefore the ultrasonic wave velocity and thickness of cortex are demanded to be predetermined for each single object and then used for the initial modeling.

Conventionally on velocity and thickness estimation, one parameter can be only calculated when the other is given, for example, the ultrasonic wave velocity can be computed by dividing the sample thickness by the measured time of flight (TOF). Many techniques have been implemented to measure speed of sound (SOS) and broadband ultrasound attenuation (BUA) specially adapted to bone tissue study [4][5][6]. Different from the conventional methods with only the main pulses used for analysis, the improved methods analyze and apply the multiple pulses in transmission or reflection signals to the parameter estimation in order that the thickness and velocity can be simultaneously assessed. This improved estimation method has been utilized to investigate the SOS and thickness of porous composites at the same time [7][8]. Recently Loosvelt and Lasaygues [9] applied the multiplepulse method to the bone study using low frequency transducers. The wavelet-based processing (WBP) method was developed to identify the desired multiple transmission or reflection pulses from main pulses in the case of overlapped signals. The results demonstrate a mean estimated error ranged from $1 \%$ to $3.5 \%$ and are comparable to those reference values from the physical measurements. Moreover, the WBP method in transmission and echo modes was applied to the thin bone sample assessment, whose thickness is approximate or smaller than the ultrasound wavelength used in ultrasonic imaging, and the results match well with the mechanical measurement and other ultrasonic methods using high-frequency transducers. [10][11].

\section{METHODS AND EXPERIMENTS}

\section{A. Transmission-echo method}

Fig. 1 illustrates the six pulses to be applied in the transmission-echo (TE) method, which are the echoes from left transmitter $t_{\mathrm{L} 1}$ and $t_{\mathrm{L} 2}$, echoes from right transmitter $t_{\mathrm{R} 1}$ and $t_{\mathrm{R} 2}$, and transmission pulses $t_{1}$ and $t_{2}$. Together with the arrival time of reference signal $t_{0}$ and the reference velocity $V_{0}$, the ultrasonic wave velocity of object sample material, $V_{\mathrm{e}}$ and the thickness of two layers, $e_{1}$ and $e_{2}$ can be calculated using the equations indicated as below:

$$
V_{e}=\frac{V_{0}\left(2 t_{0}-t_{L 1}-t_{R 1}-t_{2}+t_{1}\right)}{3 t_{1}-t_{L 1}-t_{R 1}-t_{2}}
$$




$$
e_{1}=\frac{V_{e}\left(t_{L 2}-t_{L 1}\right)}{2} \quad e_{2}=\frac{V_{e}\left(t_{R 2}-t_{R 1}\right)}{2}
$$

The most important step for TE method is the TOF determination for different pulses, especially for the multiple reflection or transmission pulses. Therefore the WBP method originated from the Meyer-Jaffard algorithm are introduced to improve the accuracy and robustness of TOF measurements. The wavelet decomposition method applies orthonormal properties on the dyadic grid, which will result in the coefficients on particular scale and correspondingly lead to the locations of TOF [9].

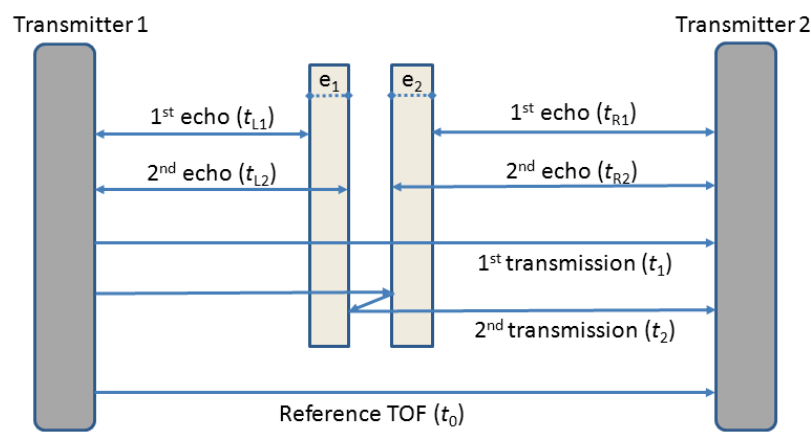

Fig. 1. The schematic of transmission-echo (TE) method in UCT.

\section{B. Samples and experimental setup}

Sixteen bovine cortex thin plates whose thickness is ranged from 0.93 to $2.32 \mathrm{~mm}$ were paired to compose 22 double-layer bone model samples for the measurement. The samples are divided into two categories according to different orientations of bone matrix: radial direction or transverse direction i.e. perpendicular to the radial direction. Only the samples from the same matrix orientation category can be paired in order to keep the consistency of bone properties, e.g. the acoustic velocities. The paired samples were aligned with their surfaces parallel to each other and then attached at both edges by reusable adhesive putty with 1-2 cm distance aparted.

The thickness of samples was physically measured by caliper and the velocities have been estimated during the previous work [11]. These results are proposed as the reference values and compared with the results from TE method. It is to be noticed that the average velocity of each pair of samples was calculated and used as the reference since TE method is only able to estimate one value of velocity for both samples in the pair. In the latter manuscript, the measured thickness from caliper and TE method will be correspondingly denoted as "caliper" and "TE", and the velocities from the previous echo experiments and TE method will be denoted as "WBP" and "TE", respectively.

Two pairs of immersion transducers with different nominal frequencies were applied to the measurements. The $1 \mathrm{MHz}$

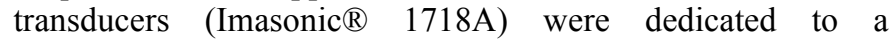
preliminary study of the TE method in the exceptionally small scale of thickness $(0.3 \sim 0.7$ wavelength which is $\sim 3.4 \mathrm{~mm}$ in bone tissue). The focus transducers with the nominal frequency
2.25MHz (Imasonic $\circledR 1719 \mathrm{~A}$ ) were then used for the accuracy and precision ${ }^{\alpha}$ ass $\beta_{s} \bar{T}$ ient of tie methold. In this case, the sample thickness is range in 0.6 to 1.5 times of the wavelengths $(\sim 1.5 \mathrm{~mm}$ in bone tissue).

Fig. 2 shows the experimental setup for the TE method. The sample was firstly fixed in a specially designed aluminum frame and then placed at the focal spots of the pair of transducers $(\sim 90 \mathrm{~mm}$ for the $1 \mathrm{MHz}$ and $\sim 150 \mathrm{~mm}$ for the $2.25 \mathrm{MHz}$ ). The reference signals were collected without the frame in between before the sample measurement. In the case of $2.25 \mathrm{MHz}$ focus transducers, the samples were placed vertical to water level as shown in the figure so that the diverged ultrasound fan-beam can penetrate samples in the center position and cover contact areas as large as possible. The bone surfaces were parallel to the transducer surface to reduce energy loss due to the incident angles. The waveform generator (TTI® TGA1241) was employed to produce the target source wavelet for the TE method.

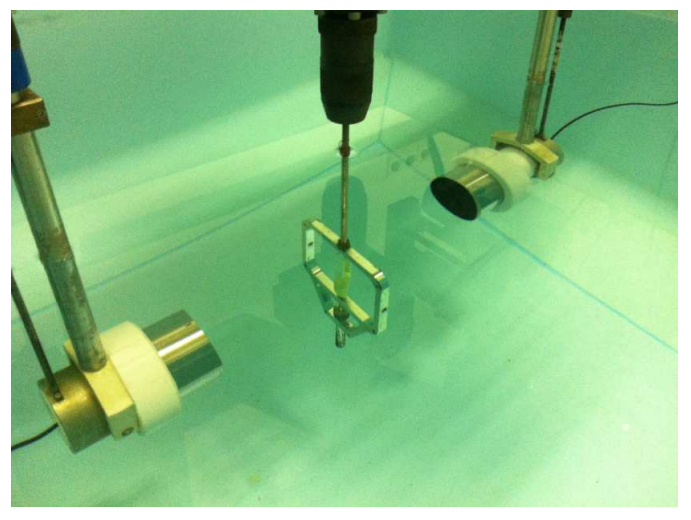

Fig. 2. The experimental device for the TE method.

\section{RESULTS AND DISSCUSSIONS}

\section{A. Preliminary results with low frequency transducer}

Since the ultrasound wavelength in bone tissue at the nominal frequency of $1 \mathrm{MHz}$ is about $3.4 \mathrm{~mm}$ which is more than twice thickness of some samples, only nine pairs of thicker samples were applied for this preliminary study. Table 1 summarizes the measurement results for the nine pairs of double-layer thin bone samples using $1 \mathrm{MHz}$ transducers. Among all measurements, three groups (1, 6 and 9) with the least thickness $(<0.4$ wavelength) are failed for the estimation, two groups (3 and 7$)$ with the most thickness $(>0.6$ wavelength) provide the best estimation, and other groups (2, 4, 5 and 8) are only successful on the velocity estimation.

For cortical thickness estimation, since the ultrasonic wavelength is about $3.4 \mathrm{~mm}$, thus theoretically the thickness larger than half wavelength $(\sim 1.7 \mathrm{~mm})$ can be measured. As shown in Table 1, the relative errors referring to caliper of 6 measurements with sample thickness larger than $1.7 \mathrm{~mm}$ are ranged from $3.74 \%$ to $7.69 \%$, while other samples present very unpredictable results, some errors are more than $100 \%$, and 4 measurements are completely failed to obtain the thickness. 
The mean error of the 6 "proper" measurements, whose sample thickness is larger than half wavelength, is $4.87 \%$.

For acoustic velocity estimation, the TE method shows better performance, most samples can be measured, the relative errors (referring to the results measured by WBP echo method and single sample [11]) are ranged from $0.02 \%$ to $11.07 \%$, and the mean error is as low as $4.65 \%$. Furthermore the velocity estimation is less influenced by sample thickness, the relative errors are more consistent in the different thickness range, and the measurements are failed only in the extreme condition of very thin samples $(<0.4$ wavelength).

TABLE 1. The measured thickness and velocity for nine pairs of double-layer thin bone samples using $1 \mathrm{MHz}$ transducers.

\begin{tabular}{|c|c|c|c|c|c|c|c|c|c|}
\hline \multirow{2}{*}{$\begin{array}{c}\text { Sample } \\
\text { Pairs }\end{array}$} & \multicolumn{3}{|c|}{ Left thickness } & \multicolumn{3}{c|}{ Right thickness } & \multicolumn{3}{c|}{ Velocity } \\
\cline { 2 - 11 } & $\begin{array}{c}\text { Caliper } \\
(\boldsymbol{m m})\end{array}$ & $\begin{array}{c}\boldsymbol{T E} \\
(\boldsymbol{m m})\end{array}$ & $\begin{array}{c}\text { Error } \\
(\%)\end{array}$ & $\begin{array}{c}\text { Caliper } \\
(\boldsymbol{m m})\end{array}$ & $\begin{array}{c}\boldsymbol{T E} \\
(\boldsymbol{m m})\end{array}$ & $\begin{array}{c}\text { Error } \\
(\%)\end{array}$ & $\begin{array}{c}\boldsymbol{W B P} \\
(\boldsymbol{m} / \mathbf{s})\end{array}$ & $\begin{array}{c}\boldsymbol{T E} \\
(\boldsymbol{m} / \mathbf{s})\end{array}$ & $\begin{array}{c}\text { Error } \\
(\%)\end{array}$ \\
\hline 1 & 1.06 & - & - & 0.98 & 1.65 & 68.37 & 3361 & - & - \\
\hline 2 & 1.33 & 3.19 & 139.85 & 1.29 & 2.95 & 128.68 & 3489 & 3665 & 5.05 \\
\hline 3 & 2.32 & 2.18 & 6.03 & 1.82 & 1.96 & 7.69 & 3404 & 3206 & 5.82 \\
\hline 4 & 1.64 & 1.91 & 16.46 & 2.14 & 2.22 & 3.74 & 3390 & 3383 & 0.20 \\
\hline 5 & 1.51 & 3.6 & 138.41 & 1.24 & 3.09 & 149.19 & 3527 & 3917 & 11.07 \\
\hline 6 & 0.98 & - & - & 1.06 & 1.73 & 63.21 & 3361 & - & - \\
\hline 7 & 1.82 & 1.96 & 7.69 & 2.32 & 2.2 & 5.17 & 3404 & 3209 & 5.72 \\
\hline 8 & 2.14 & 2.22 & 3.74 & 1.64 & 3.53 & 115.24 & 3390 & 3391 & 0.02 \\
\hline 9 & 1.24 & - & - & 1.51 & - & - & 3527 & - & - \\
\hline
\end{tabular}

\section{B. Methodology evaluation with high frequency}

\section{1) Thickness measurement}

Among 22 pairs of samples, there are still 4 measurements failed for the thickness assessment due to irregular shapes, inhomogeneous physical properties and improper location of samples; the relative errors of failed measurements are as high as $36 \%$ to $63 \%$. These data points are exclusive from the latter analysis.

Fig. 3 illustrates the relative errors of all other 40 successful measurements in the ascending order of sample thickness. Of all measurements, the errors are ranged from $0 \%$ to $22.58 \%$. The relative errors are apparently decreased with the increase of sample thickness. Table 2 lists the statistical results of thickness measurements in three different ranges: smaller than $1 \mathrm{~mm}$ ( $\sim 0.7$ wavelength), 1-1.6mm (0.7-1 wavelength) and larger than $1.6 \mathrm{~mm}(>1$ wavelength). It is depicted that the group with larger thickness shows much smaller average errors $(4.29 \%$ and $5.88 \%)$ than the small thickness group $(12.16 \%)$, especially in the condition that the thickness is smaller than $1 \mathrm{~mm}$ ( $\sim 0.7$ wavelength), the errors can be up to $22 \%$. The reason for this discrepancy can be contributed to uncertainty of TOF estimation for Eq. (2) due to serious interference between the two echoes from inner and outer surfaces in the case of thin samples.

The overall mean error of $2.25 \mathrm{MHz}$ frequency measurements is $7.13 \%$, which is slightly higher than the results from $1 \mathrm{MHz}$ frequency measurements $4.87 \%$. The lower attenuation due to lower nominal frequency of transducers can result in the more penetration of ultrasound waves, and moreover the larger amplitudes of signals and higher signal-to- noise ratio (SNR). Therefore the lower frequency provides the better performance for thickness measurements.

Lastly the correlation coefficient between caliper measurements and TE method is 0.9628 . This result indicates the notable consistency between physical measurement and ultrasonic method.

\section{2) Velocity estimation}

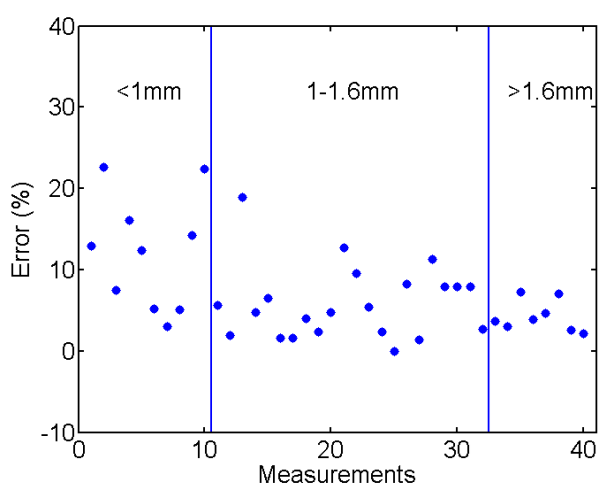

Fig. 3. The relative errors of sample thickness referring to caliper measurement for all 40 successful measurements using the TE method at nominal frequency of $2.25 \mathrm{MHz}$ in the ascending order of sample thickness.

TABLE 1 . The thickness measurements in different ranges.

\begin{tabular}{|c|c|c|}
\hline $\begin{array}{c}\text { Thickness } \\
\text { Range }\end{array}$ & $\begin{array}{c}\text { No. of } \\
\text { Measurements }\end{array}$ & $\begin{array}{c}\text { Average } \\
\text { Relative } \\
\text { Error }\end{array}$ \\
\hline$<1.0 \mathrm{~cm}$ & 10 & $12.16 \%$ \\
\hline $1.0-1.6 \mathrm{~cm}$ & 22 & $5.88 \%$ \\
\hline$>1.6 \mathrm{~cm}$ & 8 & $4.29 \%$ \\
\hline Overall & 40 & $7.13 \%$ \\
\hline
\end{tabular}

Fig. 4 shows the calculated relative errors of estimated velocity using TE method referring to the WBP method in the ascending order of combined sample thickness which is sum of the thickness of measured pair of samples. The combined sample thickness is ranged from $1.91 \mathrm{~mm}$ to $4.14 \mathrm{~mm}$, and the errors are ranged from $0.04 \%$ to $12.20 \%$. There are no apparent influences of various sample thicknesses on velocity estimation. It is different from the case of thickness measurement, in which the accuracy of estimation is greatly improved with the increase of sample thickness. It can be derived that the independency of velocity measurement from cortical thickness in WBP method results in more stable estimation of velocities in TE method [11].

However, a small trend of increasing errors is appeared with the increased combined thickness. Table 3 summarizes the calculated average relative errors for four groups of different combined thickness ranges. It is depicted that the groups with larger thickness shows a slightly higher average errors, except the fourth group including only one sample pair which could be an exceptional case during the measurement. In addition, the overall relative error of all 22 samples pairs measured by $2.25 \mathrm{MHz}$ transducers is $5.88 \%$, which is also slightly larger than the average error of $4.65 \%$ from $1 \mathrm{MHz}$ transducers. Both cases indicate that the estimation accuracy will be affected by attenuation of bone tissues. In the cases of larger combined 
thickness and higher nominal frequency of transducers, the relative errors of estimated velocities are increased, for the higher attenuation introduces more noises and scattering interferences to the signals moreover leads to a lower SNR.

The mean velocities estimated by the WBP and TE method are $3378 \mathrm{~m} / \mathrm{s}$ and $3280 \mathrm{~m} / \mathrm{s}$ for the samples with radial bone matrix direction, $3456 \mathrm{~m} / \mathrm{s}$ and $3389 \mathrm{~m} / \mathrm{s}$ for transverse matrix direction respectively. These results are approximate to each other. The smaller magnitudes in the TE method possibly result from the long term preservation and exposure to low temperature between the TE and WBP experiments. However, the TE method demonstrates much larger variation than the WBP method; the standard deviations (STD) of TE method are $220 \mathrm{~m} / \mathrm{s}$ and $263 \mathrm{~m} / \mathrm{s}$ for radial and transverse groups, which are much higher than the STDs of WBP method $(20 \mathrm{~m} / \mathrm{s}$ and 56 $\mathrm{m} / \mathrm{s}$ ) for the same bone samples. The variation of velocity measurement may arise from the more complex structures of the models used by TE method. Firstly, the double bone layers produce longer propagation path and more energy loss of ultrasound waves. Secondly, the refraction and reflection during the propagation can generate more scattering and diffraction influences on signals and then arise the uncertainty of TOF detection, especially for the main and multiple transmission pulses $t_{1}$ and $t_{2}$. Despite of large variation, the estimated velocities from TE method show similar properties as the WBP method. For example, the velocities of the radial direction group are both smaller than the transverse direction group, and the STDs of transverse group are both larger than the radial direction group. It is indicated that the TE method is a consistent and robust approach for the velocity estimation even under the condition of more complex structures.

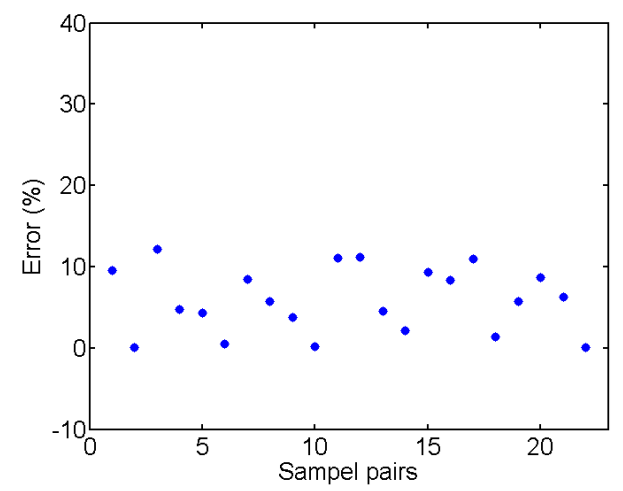

Fig. 4. The relative errors of ultrasonic wave velocities referring to the WBP echo method for all 22 pairs of samples using the TE method at nominal frequency of $2.25 \mathrm{MHz}$ in the ascending order of combined thickness.

TABLE 2. The statistical results of velocity estimation in different combined thickness ranges which is calculated by adding the thickness of the measured pair of samples together.

\begin{tabular}{|c|c|c|}
\hline $\begin{array}{c}\text { Combined } \\
\text { Thickness } \\
\text { Range }\end{array}$ & $\begin{array}{c}\text { No. of } \\
\text { Pairs }\end{array}$ & $\begin{array}{c}\text { Average } \\
\text { Relative } \\
\text { Error }\end{array}$ \\
\hline$<2.0 \mathrm{~mm}$ & 2 & $4.80 \%$ \\
\hline $2.0-3.0 \mathrm{~mm}$ & 13 & $6.02 \%$ \\
\hline $3.0-4.0 \mathrm{~mm}$ & 6 & $6.90 \%$ \\
\hline$>4.0 \mathrm{~mm}$ & 1 & $0.04 \%$ \\
\hline Overall & 22 & $5.88 \%$ \\
\hline
\end{tabular}

\section{CONCLUSIONS}

The transmission-echo method provides a feasible and reliable means to simultaneously assess the thickness and ultrasonic wave velocity for double-layer thin bone samples which can be performed as a mimic model of long bones measured in UCT. In the case of effective thickness estimation, i.e. the thickness is larger than half ultrasound wavelength, 40 out of 44 measurements are successfully assessed and the success rate is above $90 \%$. The average relative errors of sample thickness measurement are $4.87 \%$ and $7.13 \%$ for $1 \mathrm{MHz}$ and $2.25 \mathrm{MHz}$ transducers respectively. The results demonstrate good agreement to caliper measurement with correlation coefficient of 0.9628 . For ultrasonic wave velocity estimation, all pairs with effective sample thickness are successfully measured, and the mean relative errors are $4.65 \%$ for $1 \mathrm{MHz}$ and $5.88 \%$ for $2.25 \mathrm{MHz}$ transducers. Moreover, the TE method shows more robustness and stability during velocity measurement since the results are less influenced by the difference of sample properties such as thickness. For both thickness and velocity measurement, the experiments in low frequency provide more accurate estimations than high frequency, however as the disadvantage, the larger wavelength will result in the lower resolution on thickness estimation. However the method reveals sensitivities on complex structures of subjects, for example irregular shapes of bone samples and parallel alignment of two layers. Nevertheless, the transmission-echo method shows a potential to simultaneously estimate the cortical thickness and ultrasonic wave velocity for long bone model, which can be applied to improve the initial modeling for the UCT.

\section{REFERENCES}

[1] P. Lasaygues, E. Ouedraogo, J.-P. Lefebvre., M. Gindre, M. Talmant, P. Laugier, Progress toward in vitro quantitative imaging of human femur using Compound Quantitative Ultrasonic Tomography, Phys. Med. Biol., 50 (11) (2005) 2633-2649.

[2] P. Lasaygues, Assessing the cortical thickness of long bone shafts in children, using two-dimensional ultrasonic diffraction tomography, Ultrasound in Med.\& Biol, 32(8) (2006) 1215-1227.

[3] P. Lasaygues, L. Le Marrec, Ultrasonic reflection tomography vs. canonical body approximation: experimental assessment of an infinite elastic cylindrical tube, Ultrasonic Imaging, 30(1) (2008) 29-43.

[4] C.M. Langton, A.V. Ali, C.M. Riggs, G.P. Evans, W. Bonfield, A contact method for the assessment of ultrasonic velocity and broadband attenuation in cortical and cancellous bone, Clinical Physics and Physiological Measurement, 11(3) (1990) 243-249.

[5] S. Chaffa, F. Peyrin, S. Nuzzo, R. Porcher, G. Berger, P. Laugier, Ultrasonic characterization of human cancellous bone using transmission and backscatter measurements: relationships to density and microstructure, Bone, 30(1) (2002) 229-237.

[6] R. Zheng, L.H. Le, M.D. Sacchi, E. Lou, Broadband Ultrasound Attenuation Measurement of Long Bone Using Peak Frequency of the Echoes, IEEE Transaction on Ultrasonics, Ferroelectrics, and Frequency Control, 56(2) (2009) 396-400.

[7] D.K. Hsu, M.S. Hughes, Simultaneous ultrasonic velocity and sample thickness measurement and application in composites, J. Acoust. Soc. Am., 92(2) (1992) 669-675.

[8] Y.H Kim, S.J. Song, J.K. Lee, Simultaneous measurements of the ultrasonic wave velocity and thickness of a solid plate made from one side of the plate, Meas. Sci. Technol., 14 (2003) N13-N16. 
[9] M. Loosvelt, P. Lasaygues, A wavelet-based processing method for simultaneously determining ultrasonic velocity and material thickness, Ultrasonics, 51 (2011) 325-339.

[10] R. Zheng, E. Lefevre, C. Baron, and P. Lasaygues, Thin Bone Sample Assessment Using Ultrasonic Transmitted Signals Based on Wavelet Processing Method, The 4th International Congress on Ultrasonics, Singapore, May 2-5, 2013
[11] R. Zheng, P. Lasaygues, E. Lefevre and C. Baron, Thickness and velocity assessment of thin bone sample using a single signal base on wavelet analysis method, submitted to Special Issue of Ultrasonics on "Application of Ultrasound to the Diagnosis and Treatment of Bone Diseases", 2013. 